\title{
Mental wellbeing among people affected by leprosy in the Terai region, Nepal
}

\author{
Wiebrich J. van Netten ${ }^{\mathrm{a}}$, Marloes M. A. R. van Dorst ${ }^{\mathrm{a}}$, \\ Mitzi M. Waltz ${ }^{\mathrm{a}}$, Basu D. Pandeyc ${ }^{\mathrm{c}}$, Dambar Aley ${ }^{\mathrm{d}}$, \\ Ramesh Choudhary ${ }^{\mathrm{d}}$ \& Wim H. van Brakel ${ }^{\mathrm{b}}$ \\ ${ }^{a}$ Vrije University Amsterdam, The Netherlands; \\ ORCIDs: https://orcid.org/0000-0001-6285-443X; https://orcid.org/0000-0 \\ 002-9089-2545 \\ ${ }^{\mathrm{b}}$ NLR, Amsterdam, The Netherlands; \\ ORCID: https://orcid.org/0000-0002-0277-2907 \\ 'Sukra Raj Tropical and Infectious Disease Hospital, Ministry of Health and \\ Population, Nepal \\ ${ }^{\mathrm{d}}$ Lalgadh Leprosy Hospital Services Centre, P.O. Box 45600, Janakpur, \\ Nepal
}

Submitted 25 September 2020; Accepted 12 January 2021

\begin{abstract}
Summary
Objectives: The relationship between leprosy, stigma and poor mental health is well recognized. The overall objective of this study was to help improve mental wellbeing in people affected by leprosy by gaining more insight into what factors related to cultural, social and personal life influence mental wellbeing amongst people affected by leprosy in the Terai region, Nepal.

Methods: We adopted a qualitative approach with purposive sampling to include people affected by leprosy in the Terai region of Nepal. Fourteen people with various leprosy disability grades and two healthcare workers were recruited for in-depth interviews. We used a framework analysis method with characteristics of the Grounded Theory Approach. Predetermined themes were explored, and new themes brought up during the interviews were also analysed.

Results: Leprosy-related stigma still persists in the Terai region, negatively influencing mental wellbeing. A higher disability grade can result in a poorer mental wellbeing. Additional key factors influencing mental wellbeing include: people's feelings and experiences regarding leprosy, family and community, work and culture.

Conclusions: The mental wellbeing of the respondents was negatively influenced by direct and indirect consequences of being affected by leprosy. Stigma, disability grade, family, community, work and culture are very important factors that influence mental wellbeing in the Terai region, Nepal. We recommend that interventions should include a combination of strategies, including lay and peer counselling, socio-economic rehabilitation and involvement of community and family to improve the mental wellbeing
\end{abstract}

Correspondence to: Wiebrich J. van Netten, Vrije University Amsterdam, De Boelelaan 1105, 1081 HV, Amsterdam, The Netherlands (e-mail: wiebrich.van.netten@hotmail.com) 
of those affected. We also recommend using a holistic and gender-specific approach when developing these interventions.

Keywords: Leprosy, mental wellbeing, stigma, Nepal, NTD

\section{Background}

Neglected tropical diseases (NTDs) are a group of communicable diseases that are present in 149 countries. NTDs predominantly affect people living in poverty. ${ }^{1}$ One of the NTDs prioritized by the WHO is leprosy. ${ }^{2}$ Leprosy is a bacterial infection caused by Mycobacterium leprae, which affects the skin, nervous system, inner lining of the respiratory tract, and eyes, and can eventually lead to physical impairment. ${ }^{3}$ Leprosy is curable, but unfortunately it is often diagnosed after impairments have become permanent. ${ }^{4}$

Leprosy is still endemic in many regions of the world, with 208,619 new cases diagnosed in 2018.5 In Nepal, 21 districts reported a prevalence higher than 1 case per 10,000, which means that in these areas leprosy is still officially a public health problem. ${ }^{6}$

This study was conducted at the Lalgadh Leprosy Hospital \& Service Centre (LLHSC) in the southern Terai region, with a catchment area encompassing the districts Dhanusha, Mahottari, Sarlahi and Sindhuli (Province-2 of Nepal's political geography). ${ }^{6,7}$ Of the 2888 new cases found in Nepal in 2017/2018, 34\% (982 cases) were detected in Province-2, with a prevalence rate of 1.63 .6

The relationship between NTDs and stigma is well-known. ${ }^{8-10}$ In addition, it is now increasingly recognized that, together with other factors related to NTDs that can reduce quality of life, stigma can be detrimental to mental health. People with leprosy are often stigmatized, discriminated against, and excluded from social participation through a combination of external participation restrictions and impairments. These combined factors may cause affected people to be at an increased risk for mental distress, depression, anxiety and other disorders, resulting in decreased mental wellbeing. ${ }^{11-16}$

Many studies have reported on the poor mental health status of leprosy-affected people. A study in Ethiopia reported a prevalence of mental distress of 52.4\% among leprosy-affected people, compared to $7.9 \%$ in people affected by other skin conditions (odds ratio $(O R)=7.14$ ). A strong association between physical disability and mental distress was found. ${ }^{17}$ In Indonesia, Van Brakel et al. found that $60 \%$ of leprosy-affected people experienced problems with social participation, and $36 \%$ reported that they anticipated stigma. ${ }^{18}$ The main psychosocial problems reported included shame, embarrassment, difficulties with finding a marriage partner and problems finding paid work. In addition, Scott found a high number of leprosy-affected people with suicidal thoughts $(n=11 / 30){ }^{19}$ Two studies conducted in Bangladesh showed that, compared to the general population, quality of life and general mental health scores were lower in leprosy patients, and they were more likely to be depressed. ${ }^{20,21}$

While numerous studies show a relationship between leprosy and mental wellbeing, to our knowledge there have been no studies on the factors influencing mental wellbeing among people affected by leprosy in the Terai region, Nepal. Identifying these factors will help to inform development of suitable and effective interventions to promote mental wellbeing. Therefore, research was undertaken to gain more insight into factors influencing mental wellbeing among people affected by leprosy in this region. Several sub-questions were formulated to answer the main research question: 
- What are people's feelings and experiences regarding being affected by leprosy?

- Which factors in social and daily life affect mental wellbeing of people affected by leprosy in the Terai Region?

- Which cultural factors affect mental wellbeing among people affected by leprosy in the Terai Region?

- What is the effect of participation in self-help groups on mental wellbeing among people affected by leprosy in the Terai Region?

\section{Methods}

STUDY DESIGN

A cross-sectional explorative study design was employed.

\section{SAMPLING}

The study population from which the sample was selected were people affected by leprosy who lived in the districts Dhanusha, Mahottari and Sarlahi. These individuals were found via self-help groups (SHGs) run by LLHSC. The SHGs are part of the programme organized by LLHSC that provides active community outreach, social support and training for people affected by either lymphatic filariasis or leprosy, or who are otherwise disabled or marginalized. Each SHG has about 20 members.

Purposive maximum variation sampling was used in order to generate rich, appropriate and useful data. The disability grades of the interviewees were assessed according to the WHO's grading system for leprosy. ${ }^{22}$ The inclusion criteria for participants were: people who are affected by leprosy, are 18 years of age or older, and who have participated in an SHG for longer than three months. This sample included people who were cured from leprosy and therefore did not take any medication but were still affected by the consequences and/or impairments caused by the disease. Excluded were people who were not resident in the area, who were unable to understand and speak Maithili (the local language) fluently enough to answer questions, people who were marginalized because of another disease, and those who had a major comorbidity (e.g. tuberculosis, lymphatic filariasis or other major impairment). In addition, two expert interviews were conducted with local healthcare workers from the LLHSC to elaborate on important findings during the study.

\section{SAMPLE SIZE}

The number of leprosy-affected participants included in the study was determined by data saturation, i.e. sampling was continued until it seemed that most or all perceptions had been uncovered and additional data collection no longer provided additional insight into the issues being studied. This study aimed to reach data saturation.

\section{DATA COLLECTION METHODS}

Semi-structured interviews were used to ensure key topics were covered, while allowing room for respondents to tell their personal stories. Pilot interviews were conducted with an interview guide prepared beforehand to test the interview guide and the method. The interview guide themes were based on several sources that explored the relationship between NTDs and mental wellbeing, including three questionnaires-the PHQ-9, the WEMWBS and the EMIC Stigma Scale (Explanatory Model Interview Catalogue). ${ }^{11-13,18,23-25}$ Multiple factors emerged, which functioned as the structure for the interview guide. These factors were: work 
life, private life, public life, personal thoughts and opinions, and SHGs. During the research, the theme of personal thoughts and opinions proved to be a difficult topic to discuss, so the interview guide was adapted accordingly. Gender emerged as a missing factor and was therefore added to the interview guide.

DATA ANALYSIS

The interviews were audio-recorded, and an interpreter was present to translate from Maithili into English. Subsequently, the translators made a verbatim transcription in English from the audio recordings. The transcripts were read thoroughly and discussed with the interpreters. The transcripts were coded based on themes/topics from the framework using the qualitative analysis programme ATLAS-ti (Berlin: ATLAS.ti Scientific Software Development GmbH). A Framework Analysis method was used to analyse the data. ${ }^{26}$ However, since new topics brought up during the interviews were also included, this research and its framework also contained characteristics of the Grounded Theory Approach, using both a deductive and inductive approach. ${ }^{27}$

\section{ETHICAL CONSIDERATIONS}

Ethical approval was obtained from the Nepal Health Research Council. All participants were fully informed about the study and written consent was obtained from all participants.

\section{Results}

CHARACTERISTICS OF THE STUDY SAMPLE

This study is based on 16 interviews, conducted with 14 people affected by leprosy and two experts who work locally in the field of leprosy. Among the 14 leprosy-affected interviewees, four were men and 10 women, with an average age of 53 years (range: $35-70)$. Six interviewees were classified as having disability grade (DG) 1 and the remaining eight as DG 2. Ten respondents indicated they were illiterate, one woman was able to read and write, and three (all men) had attended primary school. Five women indicated they were not able to work; the other five attended to household work. Among the men, three were self-employed doing agricultural work and one was unable to work. Seven respondents were currently married, whereas six were widowed, and one was separated from her spouse.

\section{DISABILITY GRADE}

One factor likely to influence the mental state of people affected by leprosy is the severity of the disease and any resulting disabilities. From the very start it was clear that a higher disability grade could lead to problems in other areas of life, such as inability to work, less family support and overall poorer mental wellbeing. Almost all respondents mentioned pain and weakness in their body. Either they had to perform other tasks or were not able to do any work at all. One of the respondents had lost both of her eyes due to leprosy which caused significant and permanent impediment to her daily life experience:

'Before I was diagnosed with leprosy, I did all types of work. I brought food for my husband to Janakpur. I collected firewood and dried leaves. Now I am unable to do any work. I cannot see anymore. I am unhappy.' (Female, over 55 years of age, DG 2)

Regardless of how the medical world classifies leprosy, there seemed to be a different classification used by the people in the Terai region, also by health care workers and doctors. 
This had an impact on how people interacted and treated each other, which in turn influences mental wellbeing:

'Rural people think sunbahiri and leprosy are two kinds of diseases. Sunbahiri: skin becomes senseless, small spots on the skin, not seen by others, no ulcers (DG 2). Leprosy: worse spots on the skin, wounds, disfigurements, loss of fingers and toes, high disability grade. In the case of sunbahiri people do not hate, embarrass. In case of leprosy, people hate, discriminate and embarrass.' (Healthcare staff member, LLHSC)

\section{People's feelings and experiences regarding leprosy}

Two aspects became apparent about the way people in the Terai region answered questions related to their personal feelings and emotions. First, it became clear that many of the respondents suffered from anticipated or internalized stigma:

'Yes, I feel ashamed due to my disease. Even if you are sitting in front of me, I feel shameful. How could I sit in front of you with my disease? ... Some people said: "Aunty why you cover your whole body with clothes and sit separately?" I said "I have a disease; it hurts me and makes me shameful".' (Female, age above 55, DG 2)

One man chose to not tell anyone about the diagnosis of leprosy:

'I felt ashamed, that's why I did not tell them (family), I was worried about my disease. When I started to take medicines then they (family) knew about my disease.' (Male, age 60, DG 0)

Second, it was a challenge to ask respondents about mental wellbeing, feelings and emotions. The interpreters explained that many respondents did not receive education and were not used to talking about their feelings, consequently they had little vocabulary regarding feelings and emotions. One female respondent (age 60) cried because she did not know how to verbally express her feelings.

Most of the men explained that when asked questions about their disease they did not really feel ashamed. They mentioned the importance of work and the practical implications of the disease. As long as they could work and earn for their families, they felt fine.

'Interviewer: Do you feel afraid of people knowing about your problem?

Respondent: No, I don't feel afraid if people know about my disease. I walk freely, I am fine.' (Male, age 43, DG 1)

One male respondent gave an example from the past, showing the impact of stigma by association, but adding that he sees the situation as improving:

'Now there is no problem but before, 7 years ago, when I married off my daughter. The family of the groom did not accept my daughter due to my leprosy. They told me that she is the daughter of a leprosy-affected person. I went to the police station and won the argument.' (Male, age 47, $D G$ 2)

\section{Social and daily life factors}

FAMILY AND COMMUNITY

Respondents experienced family and community as two important factors in their daily lives. When asked to talk about their own feelings, some respondents included family and community in their answers. It seemed that many respondents typically valued themselves based on how others treated them, specifically family members and the community. One respondent did not inform his family about the diagnosis because he was afraid of further consequences. 
'Yes, sometimes I felt I was losing my self-respect due to this disease because some community people teased me while talking sometimes. I felt let down by my family. My family never cared for me.' (Female, age 60, DG 1)

"No, I felt less [unsatisfied and sad] at that time of diagnosing but my son encouraged me. He said: "it's nothing, do not worry, now you start medicine, I do not mind." ... Then what can I say.' (Male, age 60, DG 1)

However, the majority of respondents explained that there is increasing awareness about leprosy in the community. Most of the examples of negative experiences provided occurred in the past. Today, most respondents were able to sit and eat with their fellow community members and take part in social life.

WORK

Work seemed to be easy to discuss for the respondents and was a frequent topic. Mostly rural areas were visited, where most men do agricultural work and women do household work. Some respondents owned land and had domesticated animals. One woman was able to set up multiple shops as a result of the microcredit scheme, which is part of the SHGs. The next quote clearly illustrates that leprosy-affected people compared themselves with 'normal people', and the importance of fitting into the community and contribute to it. It can be implied that the absence of work inhibits the sense of self-respect that emanates from employment.

'I'm not worried about my disease. I am worried about my foot. Without it, I could not work like other normal people. I feel jealous when I see other normal people.' (Female, age 60, unemployed, $D G$ 2)

During informal conversations with men affected by leprosy who had a low disability grade, it was repeatedly said that work occupied their minds. It seems that being able to work can have a positive effect on mental wellbeing. In addition, the mental health impact of leprosy, when it affects ability to work, can cause tensions and illness, and therefore be disabling in itself.

'Every time I stay at home. I am not able to earn for us. There are 5-6 members in my family who need food and only one person who earns for us. It's out of my knowledge. Due to many tensions I found myself ill.' (Female, age 35, DG 1)

'I do business with potatoes and onions. I felt pain while doing my work. I felt weakness in my hands and legs, both. I cannot do hard work. I have to pay more money to the porter who manages all the food while I do my business.' (Male, age 60, DG 2)

\section{Cultural factors}

\section{KNOWLEDGE ABOUT LEPROSY}

There seemed to be a dualistic view regarding the aetiology and cure of leprosy. As noted, the local community has an alternative view on the classification of leprosy. In addition, they also have alternative views about the aetiology of leprosy, believing that it is caused by God or karma (see Religion), but also expressing that leprosy is an infectious, communicable disease that can be cured with medicines. It appeared that confidence in the medicine provided by local health workers was linked to a positive mental state, as the majority of the respondents mentioned that after taking medication, they felt relief.

'The past days are in the past. Now, I have taken medicines from Lalgadh. I believe that the disease cannot harm me anymore [...] If we do regular activity (soaking, self-care and medication), we will be safe from the bad effect of leprosy. Otherwise, it's harmful to us.' (Male, age 60, DG 1) 
'I suggest to people it's just a disease, you must go for treatment on time, otherwise it will infect other people in your family to. It will make you disabled. If your family gets the same symptoms send them to Lalgadh as soon as possible.' (Male, age 60, DG 1)

"When I got leprosy, I was unaware about it. In the beginning I did not take care of my disease. When the disease became worse, people said "It's leprosy." They suggested me to visit Lalgadh for treatment and I felt relief when I took medicines.' (Female, age above 55, DG 2).

\section{GENDER}

During the research it became apparent that a patriarchal social system in which the men have the authority over the women can impact mental wellbeing. This was confirmed in an expert interview:

'Iffemales have leprosy then they feel many difficulties because of their dependence on the husband and the family, they are not educated women.... These women come to us and they feel very sad, they are not working, they are not talking, they feel very shy, they are not sharing their problems.' (Healthcare staff member, LLHSC)

Most women who were interviewed were uneducated and didn't have paid work, making them dependent on their husband, or other family members in case of being widowed:

'When my husband brought me to Kathmandu for treatment, he said to me: if you will die before me it's better for you, if I will die before you, you have to face so many problems, your condition will be just like a dog...' (Female, age 60, DG 1)

During one of the expert interviews, women-only groups were discussed that include training women to work on handicrafts, and stimulating sharing experiences and emotions, which seemed to have a positive effect on the women and their mental wellbeing.

\section{RELIGION}

Religious affiliation was requested, but the factor of religion was not a topic covered by the interview questions. However, it was brought to the fore by respondents in some of the interviews. The factor of faith was mostly spoken about in relation to suffering, dying and death. Some female respondents said they wanted to die and they were praying to God for this to happen soon. Some seemed to be torn about the reasons God had for afflicting them with leprosy, and what the implications of this were:

'What should I think about my coming days? I pray to God, let me die. What should I think? Oh God, let me die, what should I think now.' (Female, Hindu, 55 years old, DG 2)

'No, I did not talk with anyone.... I should die, everyone should die one day... What mistake I made in the past, God made me like this. I am still crying day and night.' (Female, Muslim, above 55 years old, $D G$ 2)

Religion seems to be an important socio-cultural system that people turn to for answers surrounding their illness. In some interviews, respondents said faith in God gave them some comfort, or provided a way in which to deal with leprosy and the emotions that come with it.

'God gave me this, so why should I feel bad about leprosy, I don't feel shy.' (Female, Hindu, 59 years old, $D G$ 1) 


\section{Self-help groups (SHGs)}

All the respondents were part of a SHG, usually meeting every one or two weeks under a tree or other central point in the village, led by a local facilitator who is also affected by leprosy. Some of the groups have been meeting each other for years and have formed strong relational bonds. During the meetings, time is scheduled for the self-care of wounds/ulcers in addition to discussions about credit unions and microenterprise development. Furthermore, the meeting is a place where people can share their thoughts and daily life experiences, good and bad. If questions arise about leprosy or other matters, the facilitator is able to listen, explain and if needed act on it, as a central coordinator. This can include talking to non-affected people from the community or organizing help to meet the needs of a participant. One of the facilitators explained that he himself was diagnosed with leprosy and had visible disabilities and was now a respected member of the community. He was able to use his own experiences and knowledge to help and support others. In addition to the weekly gatherings with a local facilitator, peer counsellors (community staff from LLHSC) travel to all the SHGs on a monthly basis to provide further support for the group when problems arise of when extra socio-economic support is needed. When members of SHGs were asked about the activities, almost all were positive about their SHG.

'We participate in the SHG. We discuss about saving money and investments, we discuss how we should operate our group smoothly in the coming days. I really enjoy participating in the SHG.' (Male, age 60, DG 1)

The same man also explained how the members of an SHG can help stimulate other people from their village or community who are also affected to join the group.

In the beginning there were only four, five people in the SHG. I asked the doctor for the information about other people who took medicines for leprosy and convinced them to participate in the SHG. (Male, age 60, DG 1)

Another example of a positive effect of the SHGs is education and involving the local community. A local gathering usually tends to attract other locals from the village. This can start the conversation about leprosy, its effects and treatment. By starting the discussion in an open environment (under a tree or central building), the stigma can be reduced, as was explained by of the respondents:

'The facilitator of our group talked and convinced my neighbor/relative who treated me badly, to stop teasing me because of the leprosy. After that she never teased us again. The neighbor also joined the group and know understands more about leprosy.' (Female, age 35, DG 1).

One other strong effect of the SHG is that they stimulate the sense of community, bringing people together, no matter their background, sex, age or whether they are affected by a disease. Such inclusive processes were echoed by the responses from the members:

'There are so many people who participate in SHG. They sit together and talk together; I like to sit amongst them.' (Female, age 70, DG 2)

\section{Discussion}

MENTAL WELLBEING

The link between leprosy, decreased mental wellbeing, and mental health problems such as anxiety and depression has been recognized in various studies. ${ }^{17-21,28}$ Although numerous 
studies specifically highlight the need for mental health programmes, there is still a significant lack in structural attention for mental wellbeing and mental health problems for those affected. Multiple studies suggest working towards an inclusive health care programme that includes mental health and wellbeing. ${ }^{13,29-31}$

This qualitative research was part of a mixed-methods study in which the quantitative results confirmed that the mental wellbeing of people affected by leprosy in the Terai region, was significantly lower than that of the general population. ${ }^{32}$ In order to address mental wellbeing and mental health problems like depression and anxiety, this study aimed to provide a deeper understanding of the factors underlying and therefore shaping mental wellbeing of people living in the Terai region in Nepal. These will be discussed in turn.

\section{STIGMA}

The majority of respondents reported some level of internalized stigma, but few examples of enacted stigma were mentioned. This might be due to increased awareness of leprosy in the community due to the long-established public awareness programmes conducted by LLHSC. ${ }^{33,}{ }^{34}$ People reported experiences of self-stigma which could be explained by the fact that most respondents in this study were older people and grew up during a time where leprosy was still heavily stigmatized. During the interviews, many respondents recalled experiences from the past of discrimination or even abuse (physically and verbally), which could account for the ongoing internalized stigmatization. ${ }^{35}$ This is also recognized by Fung et al. ${ }^{36}$ who explain that internalized stigma can reduce self-esteem and efficacy. The quantitative part of this study also confirmed that people who indicate a higher level of experienced and perceived stigma have a lower level of mental wellbeing. ${ }^{32}$ This confirms the findings of Van Brakel et al. ${ }^{18}$ who found both anticipated and community stigma to be high in Indonesia, and described the negative effect on psychological wellbeing.

\section{SEVERITY OF DISABILITY}

As expected, more severe leprosy-related impairment had a negative impact on respondents' mental wellbeing. One respondent with visible impairment lost her eyesight due to leprosy, which prevented her from being able to go out by herself which clearly influenced her mental wellbeing negatively. Likewise, people who had no functional impairment and who were able to work and generate an income mentioned feeling satisfied. As is also described by other studies, a higher disability grade seemed to be associated with poorer mental wellbeing. ${ }^{17,}$ 20, 21 Programmes should take into account the long-lasting effects of leprosy, including physical impairment, even after finalizing their multidrug treatment. ${ }^{18,37}$ Consequently, mental wellbeing associated with impairment also needs attention, potentially including psychological treatment.

\section{DISEASE CONCEPTS}

One unexpected but interesting finding is that rural people and local healthcare staff used another classification system for leprosy. This local perspective distinguishes between sunbahiri and leprosy. The mild condition Sunbahiri (only skin patches) does not trigger stigma and discrimination, whereas people with leprosy are discriminated against. It seems that people are given some kind of reassurance when told that they 'merely' have sunbahiri, and therefore their condition may have less impact on their mental wellbeing. Since this classification is used at this moment, it should be considered when developing interventions to improve mental wellbeing for those affected. 


\section{IMPORTANCE OF FAMILY AND COMMUNITY}

Attitudes and behaviour of family members and the community appeared to greatly impact the mental wellbeing of leprosy-affected persons. Many respondents mentioned family and community when talking about the feelings they had about themselves; it appears that the thoughts and opinions of the family and community play a crucial role in how people in South Nepal tend to value themselves. This aligns with the fact that Nepal tends to be a communal culture, where emphasis is put on the family or community rather than the individual. Therefore, interventions developed to increase the mental wellbeing of people affected by leprosy should include a role for the family and community. This has been recommended by multiple previous studies. ${ }^{34,38,39}$ Furthermore, in a systematic review by Sermrittirong et al., ${ }^{40}$ Information Education and Communication (IEC) programmes that focus on awareness of leprosy in the general population were found to be effective. ${ }^{40}$

\section{POSITIVE EFFECT OF WORK}

The participants indicated that work has a positive effect, whereas inability to work caused tensions and illness, and therefore was disabling in itself. Sermrittirong and Van Brakel ${ }^{40}$ mentioned socio-economic rehabilitation (SER) as an intervention that could stimulate selfreliance. LLHSC has implemented SER as part of the Stigma Elimination Project (STEP) in the SHGs, which includes developing credit unions and microenterprises. ${ }^{33}$ This allows people to develop their own businesses and support their families. Furthermore, leprosy-affected people were shown to suffer less from internalized stigma and community stigma as a result of SHGs. ${ }^{33,41}$ This was confirmed in the present study: respondents said they felt positive about the SHG meetings. Therefore, SHGs that include SER should be actively supported and continued.

\section{KNOWLEDGE ABOUT LEPROSY}

One important aspect of the views of the respondents was dualism: there seemed to be a dualistic view among the respondents about the aetiology of leprosy and its treatment. One of the respondents stated that leprosy is a communicable disease, but at the same time said that he did not know whether he had leprosy because of committing a sin or not. The former seems to be grounded in modern medicine; the latter in a traditional worldview. Additionally, although not studied in this paper, leprosy is a disease still known in Nepal for its disfigurements along with the accompanying stigma. This means that people with a less advanced stage of leprosy either do not recognize it as being leprosy or conceal their symptoms rather than actively seeking treatment, resulting in continuing disease and risk of disfigurements. ${ }^{35,42}$ In efforts to change people's health behaviours, it is important to take into account traditional beliefs, values and practices concerning leprosy and the traditional worldview. ${ }^{43}$ Subsequently, interventions developed to increase the mental wellbeing of people affected by leprosy can be shaped to fit with their traditional way of thinking. This conclusion was also reached by Scott, ${ }^{19}$ who emphasized that religion is part of the 'psychosocial needs' of leprosy-affected people.

\section{GENDER}

Female gender emerged as an additional factor with significant influence on the mental wellbeing of leprosy-affected persons. Field trips and interviews confirmed that Nepalese culture is based on a patriarchal social system in which women tend to have a lower social status than men. Women with leprosy face more severe consequences than men, like abuse 
and divorce, but also difficulties when earning money because of fewer and lower-paid work options. This in turn leads to increased dependency on their husband or family. ${ }^{44-48}$ The terms 'double jeopardy', or 'triple jeopardy' have been used to describe the greater risk to women of experiencing discrimination. ${ }^{45,49}$

Taken together, these disparities can cause women to have a lower quality of life and decreased mental wellbeing. ${ }^{20,50,51}$ Multiple studies have stressed the importance of a gendersensitive approach when developing interventions for people affected by leprosy. ${ }^{46,52}$ Health workers should be informed about the different consequences for women and men, and their specific needs. In addition, involving local women when developing interventions that target the needs of women, especially if the majority of health workers are male, is also important. ${ }^{52}$ A final example, which is already successfully implemented at the LLHSC, is organizing women-only group meetings in which they combine crafts making and sharing experiences and emotions.

\section{SHGS AND COUNSELLING}

Almost all SHG members stated that they enjoy being part of the group and like to sit amongst them. In literature, group counselling and peer counselling for leprosy-affected people with poor mental wellbeing proved to be good methods to reduce the stigmatizing effects of leprosy. ${ }^{53,54}$ During group counselling multiple people are reached at the same time, and are made aware that they are not alone. ${ }^{53}$ Peer counselling incorporates a holistic view of the problems people experience, including personal beliefs, thoughts and feelings. ${ }^{55}$ The SHGs act as venues for informal peer counselling in a group format. Moreover, this study shows that SHGs are an effective tool to improve awareness about leprosy, its transmission, and treatment, consequently reducing the associated stigma. Many respondents explained that they have urged people to go to LLHSC to find out about treatment or to join the SHGs once diagnosed with leprosy, reducing the risk of disabilities. However, although SHGs seem to have a positive effect, the interviews revealed a need for further mental health care, as was also described by Van Dorst et al. ${ }^{32}$ Programmes supporting self-care or self-help groups should not automatically assume that these deal with mental health in an adequate way and require continuous evaluation and improvements.

\section{HOLISTIC APPROACH FOR INTERVENTIONS TARGETING MENTAL WELLBEING}

It became clear during the interviews that social and personal life factors are an integral part of the holistic understanding of the respondents' experiences of daily life with leprosy. For example, the Terai region in Nepal has a patriarchal socio-economic system. Consequently, being a woman in this area was found to have an additional negative impact on the mental wellbeing. Multiple systems of power intersect to impact those who have a lower status, favouring a holistic approach when developing interventions to improve mental wellbeing. A recent study from Bailey et al. ${ }^{29}$ reaffirmed the paramount importance of a holistic approach when targeting mental health in people with NTDs. A previous study conducted in the same region as the current study also stressed the importance of holistic approaches. ${ }^{46}$ Lusli et al. ${ }^{56}$ recommended a combination of interventions in order to fulfil all identified needs including education, socio-economic development, and involvement of community members and family members. 


\section{LIMITATIONS}

Due to a limited time frame and number of translators and logistical constraints, we were not able to interview an equal number of men and women for this study. The inclusion of more participants, in particular more men, would have helped to obtain a better understanding of the differences between men's and women's experiences and needs and the way this affected their mental wellbeing. In addition, some concepts used in Maithili could not be translated into English directly, and vice versa. Respondents had difficulty understanding psychological concepts, like pride and self-respect. Therefore, leading questions (e.g.: do you often feel sad?) were sometimes asked, potentially causing interviewer bias. Persons who were affected by leprosy but not members of an SHG were not interviewed. This population is likely to be significantly different from those who do participate in SHGs. Finally, the mean age of the sample population was high ( $>50)$ since most people who participate in SHGs are of an older age. Therefore, the findings may not be generalizable to younger leprosy-affected people.

\section{Conclusions}

We showed that the mental wellbeing of most respondents was negatively affected by the direct and indirect consequences of being affected by leprosy. Multiple types of stigma were found to persist among people in the Terai region, which negatively influences mental wellbeing. Mental wellbeing was especially affected in people who experienced a high level of physical impairment affecting daily life activities. This highlights the need for counselling or other forms of support. In addition, many social and daily life factors play a role in the mental wellbeing of those affected by leprosy. We found that family and community are two very important factors influencing the mental wellbeing of those affected. Therefore, family and community should be a part of the interventions aimed at improving mental wellbeing. Nepal has a patriarchal social system in which women have a lower social status. This causes women to face additional negative consequences, including an increased risk of lower mental wellbeing. Therefore, a gender-sensitive approach is needed to ensure that interventions are effective for women. When discussing mental wellbeing, all social and daily life factors are interconnected, jointly shaping mental health status. As a consequence, to improve mental wellbeing a holistic approach should be used when developing or implementing interventions. SHGs were found to have a positive influence on the mental wellbeing of the leprosy-affected participants while also reducing the stigma surrounding leprosy. However, a substantial number of participants still expressed signs of mental distress or depression, indicating that specific attention for the mental health of participants is important even in existing self-help groups.

\section{RECOMMENDATIONS FOR FURTHER PRACTICE AND FUTURE RESEARCH}

The present study shows that multiple types of stigma persist among people in the Terai region and that people experience poor mental wellbeing. Therefore, existing programmes (SHGs) for stigma reduction and improving mental wellbeing should continue. Since several respondents who were already members of an SHG still experienced poor mental wellbeing, additional measures (individual peer counselling) should be considered to address mental wellbeing. 
The SHGs include people with any disease or who are otherwise marginalized. Since this study only included leprosy-affected people, future research should investigate the differences in mental wellbeing between leprosy-affected and non-leprosy affected people.

Different factors intersect and exert a combined effect on mental wellbeing, so interventions aimed at improving mental wellbeing should use a holistic approach. Additional peer counselling by lay and peer counsellors could be embedded in the existing SHGs for leprosyaffected people with low mental wellbeing.

A gender-sensitive approach is needed to improve the mental wellbeing of women affected by leprosy. Health workers should be informed about the different consequences for women and their specific needs. Involving local women in the discussion of how to address the needs of women is also important. Further studies on gender-based approaches to address leprosyrelated stigma should be conducted.

\section{Acknowledgements}

This study was developed in collaboration with the Netherlands Leprosy Relief (NLR), Amsterdam which provided support throughout the research process. Without the contributions of the community staff of LLHCS, this study would not have been possible. The community staff organized and coordinated the field trips for data collection and helped with translating the interviews from Maithili into English.

\section{Author contributions}

WvN designed the research plan, performed the research, analysed the results, wrote the draft and wrote the final manuscript. MvD performed the research, helped analyse and interpret the results and revised the draft. MW helped with the design of the study, helped with interpretation of the results, supervised the study and revised the draft. BP helped with the design of the study, supervised the study, and revised the draft. DA helped with the design of the study, supervised the study and revised the draft. RC helped with conducting the study and revised the draft. WvB co-designed the research plan, helped with analysis and interpretation of the results, supervised the study and revised the draft.

\section{Disclosure statement}

None of the authors have any competing interests.

\section{Ethics and consent}

Ethical approval was obtained from the Social Sciences ethics board of VU Amsterdam and from the Nepal Health Research Council (Reg. no 79/2018).

\section{Funding information}

None.

\section{Paper context}

Leprosy is known for its stigmatizing effects including visible impairments and disabilities which may result in poor mental health. This study identified factors influencing the mental wellbeing among leprosy-affected people in the Terai region, Nepal. The most noteworthy 
being disability grade, family, community, work and culture. Furthermore, persisting leprosyrelated stigma seemed to result in a lower mental wellbeing. Interventions should adopt a combination of strategies using a holistic- and gender-specific approach.

\section{Data deposition}

Data will be available from https://www.infontd.org/resource/mental-wellbeing-among-peop le-affected-leprosy-terai-region-nepal.

\section{References}

1 WHO. Neglected tropical diseases 2019 [06-03-2018]. Available from: https://www.who.int/neglected_disease s/diseases/en/.

2 Savioli L, Daumeric D. Accelerating work to overcome the global impact of neglected tropical diseases-a roadmap for implementation, 2012.

3 WHO. Leprosy key facts 2018 [06-03-2018]. Available from: https://www.who.int/en/news-room/fact-sheets/ detail/leprosy.

4 Wilder-Smith EP, Van Brakel WH. Nerve damage in leprosy and its management. Nat Clin Pract Neurol, 2008; 4(12): 656-663.

5 WHO. Global leprosy update, 2018: moving towards a leprosyfree world, 2019.

6 Government of Nepal. Annual Report Department of Health Services 2074/75 (2017/18), 2018.

7 Lalgadh Leprosy Hospital and Services Centre (LLHSC) 2018 [06-03-2018]. Available from: http://www. nepal-leprosy.com/.

8 Hotez PJ. Stigma: the stealth weapon of the NTD. PLoS Negl Trop Dis, 2008; 2(4): e230.

9 Hotez PJ, Molyneux DH, Fenwick A, Kumaresan J, Sachs SE, Sachs JD et al. Control of neglected tropical diseases. N Engl J Med, 2007; 357(10): 1018-1027.

10 Weiss MG. Stigma and the social burden of neglected tropical diseases. PLoS Negl Trop Dis, 2008; 2(5): e237.

11 Eaton J. Mental health, stigma, and Neglected Tropical Diseases: MHIN - a global community of mental health innovators; 2017. Available from: https://www.mhinnovation.net/blog/2017/may/24/mental-health-stigma-and -neglected-tropical-diseases.

12 Hofstraat K, van Brakel WH. Social stigma towards neglected tropical diseases: a systematic review. Int Health, 2016; (8 Suppl 1): i53-i70.

13 Litt E, Baker MC, Molyneux D. Neglected tropical diseases and mental health: a perspective on comorbidity. Trends Parasitol, 2012; 28(5): 195-201.

14 Peters RM, Dadun, Zweekhorst MB, Bunders JF, Irwanto, van Brakel WH. A cluster-randomized controlled intervention study to assess the effect of a contact intervention in reducing leprosy-related stigma in Indonesia. PLoS Negl Trop Dis, 2015; 9(10): e0004003.

15 Prince M, Patel V, Saxena S, Maj M, Maselko J, Phillips MR et al. No health without mental health. The Lancet, 2007; 370(9590): 859-877.

16 Ton TG, Mackenzie C, Molyneux DH. The burden of mental health in lymphatic filariasis. Infect Dis Poverty, 2015; 4: 34.

17 Leekassa R, Bizuneh E, Alem A. Prevalence of mental distress in the outpatient clinic of a specialized leprosy hospital. Addis Ababa, Ethiopia, 2002. Lepr Rev, 2004; 75(4): 367-375.

18 van Brakel WH, Sihombing B, Djarir H, Beise K, Kusumawardhani L, Yulihane Ret al. Disability in people affected by leprosy: the role of impairment, activity, social participation, stigma and discrimination. Glob Health Action, 2012; 5: 1 .

19 Scott J. The psychosocial needs of leprosy patients. Lepr Rev, 2000; 71(4): 486-491.

20 Tsutsumi A, Izutsu T, Akramul Islam MD, Amed JU, Nakahara S, Takagi F et al. Depressive status of leprosy patients in Bangladesh: association with self-perception of stigma. Lepr Rev, 2004; 75(1): 57-66.

21 Tsutsumi A, Izutsu T, Islam AM, Maksuda AN, Kato H, Wakai S. The quality of life, mental health, and perceived stigma of leprosy patients in Bangladesh. Soc Sci Med, 2007; 64(12): 2443-2453.

22 Alberts CJ, Smith WC, Meima A, Wang L, Richardus JH. Potential effect of the World Health Organization's 2011-2015 global leprosy strategy on the prevalence of grade 2 disability: a trend analysis. Bull World Health Organ, 2011; 89(7): 487-495.

23 Kroenke K, Spitzer RL, Williams JB. The PHQ-9: validity of a brief depression severity measure. J Gen Intern Med, 2001; 16(9): 606-613.

24 Putz R, O’Hara K, Taggart F, Stewart-Brown S. Using WEMWBS to measure the impact of your work on mental wellbeing: A practice-based user guide, 2012. 
25 Weiss MG, Doongaji DR, Siddhartha S, Wypij D, Pathare S, Bhatawdekar M et al. The Explanatory Model Interview Catalogue (EMIC). Contribution to cross-cultural research methods from a study of leprosy and mental health. Br J Psychiatry, 1992; 160: 819-830.

26 Gale NK, Heath G, Cameron E, Rashid S, Redwood S. Using the framework method for the analysis of qualitative data in multi-disciplinary health research. BMC Med Res Methodol, 2013; 13: 117.

27 Green J, Thorogood N. Qualitative Methods for Health Research. London: Sage, 2014.

28 Bow-Bertrand A, Pahan D, Mangeard-Lourme J. An exploration into the psychological impact of leprosy in Sirajganj, Bangladesh. Lepr Rev, 2019; 90(4): 399-417.

29 Bailey F, Eaton J, Jidda M, van Brakel WH, Addiss DG, Molyneux DH. Neglected tropical diseases and mental health: progress, partnerships, and integration. Trends Parasitol, 2019; 35(1): 23-31

30 Rocha-Leite CI, Borges-Oliveira R, Araujo-de-Freitas L, Machado PR, Quarantini LC. Mental disorders in leprosy: an underdiagnosed and untreated population. J Psychosom Res, 2014; 76(5): 422-425.

31 Singh GP. Psychosocial aspects of Hansen's disease (leprosy). Indian Dermatol Online J, 2012; 3(3): 166-170.

32 van Dorst M, van Netten WJ, Waltz MM, Pandey BD, Choudhary R, van Brakel WH. Depression and mental wellbeing in people affected by leprosy in southern Nepal. Glob Health Action, 2020; 13(1): 1815275.

33 Cross H, Choudhary R. STEP: an intervention to address the issue of stigma related to leprosy in Southern Nepal. Lepr Rev, 2005; 76(4): 316-324.

34 Varkevisser CM, Lever P, Alubo O, Burathoki K, Idawani C, Moreira TM et al. Gender and leprosy: case studies in Indonesia, Nigeria, Nepal and Brazil. Lepr Rev, 2009; 80(1): 65-76.

35 Heijnders ML. The dynamics of stigma in leprosy. Int J Lepr Other Mycobact Dis, 2004; 72(4): 437-447.

36 Fung KM, Tsang HW, Corrigan PW, Lam CS, Cheung WM. Measuring self-stigma of mental illness in China and its implications for recovery. Int J Soc Psychiatry, 2007; 53(5): 408-418.

37 Raposo MT, Reis MC, Caminha AVQ, Heukelbach J, Parker LA, Pastor-Valero M et al. Grade 2 disabilities in leprosy patients from Brazil: need for follow-up after completion of multidrug therapy. PLoS Negl Trop Dis, 2018; 12(7): e0006645.

38 de Stigter DH, de Geus L, Heynders ML. Leprosy: between acceptance and segregation. Community behaviour towards persons affected by leprosy in eastern Nepal. Lepr Rev, 2000; 71(4): 492-498.

39 Rafferty J. Curing the stigma of leprosy. Lepr Rev, 2005; 76(2): 119-126.

40 Sermrittirong S, Van Brakel WH, Bunbers-Aelen JFG. How to reduce stigma in leprosy-a systematic literature review. Lepr Rev, 2014; 85(3): 149-157.

41 Ebenso B, Fashona A, Ayuba M, Idah M, Adeyemi G, S-fada S. Impact of Socio-Economic Rehabilitation on leprosy stigma in Northern Nigeria: findings of a retrospective study. Asia Pac Disabil Rehabil J, 2007; 18(2): 98-119.

42 Subedi M, Engelbrektsson UB. Factors contributing to delay in diagnosis and start of treatment of leprosy: analysis of help-seeking narratives from a community study in Dang district. Dhaulagiri J Sociol Anthropol, 2018; 18: 11-17.

43 Opala J, Boillot F. Leprosy among the limba: illness and healing in the context of world view. Soc Sci Med, 1996; 42(1): 3-19.

44 Department of Mental Health and Substance Abuse. Gender disparities in mental health. Dependance DoMHaS, 2013.

45 Morrison A. A women with leprosy is in double jeopardy. Lepr Rev, 2000; 71: 128-143.

46 Try L. Gendered experiences: marriage and the stigma of leprosy. Asia Pac Disabil Rehabil J, 2006; 17(2): 55-72.

47 Ulrich M, Zulueta AM, Caceres-Dittmar G, Sampson C, Pinardi ME, Rada EM et al. Leprosy in women: characteristics and repercussions. Soc Sci Med, 1993; 37(4): 445-456.

48 van 't Noordende AT, van Brakel WH, Banstola N, Dhakal KP. The impact of leprosy on marital relationships and sexual health among married women in Eastern Nepal. J Trop Med, 2016; 2016: 4230235.

49 Griffey H. International Federation of Anti-leprosy Associations. Triple jeopardy: tackling the discrimination facing girls and women with leprosy, 2015.

50 Dijkstra JIR, Van Brakel WH, Van Elteren M. Gender and leprosy-related stigma in endemic areas: A systemic review. Lepr Rev, 2017; 88(3): 419-440.

51 Mankar MJ, Joshi SM, Velankar DH, Mhatre RK, Nalgundwar AN. A comparative study of the quality of life, knowledge, attitude and belief about leprosy disease among leprosy patients and community members in Shantivan Leprosy Rehabilitation centre, Nere, Maharashtra, India. J Glob Infect Dis, 2011; 3(4): 378-382.

52 Vlassoff C, Khot S, Rao S. Double jeopardy: women and leprosy in India. World Health Stat Q, 1996; 49(2): $120-126$.

53 Floyd-Richard M, Gurung S. Stigma reduction through group counselling of persons affected by leprosy-a pilot study. Lepr Rev, 2000; 71(4): 499-504. 
54 Lusli M, Peters R, van Brakel W, Zweekhorst M, Iancu S, Bunders J et al. The impact of a rights-based counselling intervention to reduce stigma in people affected by leprosy in Indonesia. PLoS Negl Trop Dis, 2016; 10(12): e0005088.

55 Van Brakel WH, Voorend C, Ebenso B, Cross H, Augustine V. ILEP-Guidelines to reduce stigma Guide 1. London/Amsterdam: The International Federation of Anti-Leprosy Associations (ILEP) and the Netherlands Leprosy Relief (NLR), 2011.

56 Lusli M, Peters RM, Zweekhorst MB, Van Brakel WH, Seda FS, Bunders JF et al. Lay and peer counsellors to reduce leprosy-related stigma-lessons learnt in Cirebon, Indonesia. Lepr Rev, 2015; 86(1): 37-53. 